\title{
Multi-Function Operating Machine: A Conceptual Model
}

\author{
${ }^{1}$ Sharad Srivastava , ${ }^{2}$ Shivam Srivastava,${ }^{3}$ C.B.Khatri \\ ${ }^{1,2,3}$ Shri Ramswaroop Memorial Group of Professional College Lucknow, Uttar Pradesh.
}

\begin{abstract}
This paper presents the concept of Multi-Function Operating Machine mainly carried out for production based industries. Industries are basically meant for Production of useful goods and services at low production cost, machinery cost and low inventory cost. Today in this world every task have been made quicker and fast due to technology advancement but this advancement also demands huge investments and expenditure, every industry desires to make high productivity rate maintaining the quality and standard of the product at low average cost. We have developed a conceptual model of a machine which would be capable of performing different operation simultaneously, and it should be economically efficient .In this machine we are actually giving drive to the main shaft to which scotch yoke mechanism is directly attached, scotch yoke mechanism is used for sawing operation. On the main shaft we have use bevel gear system for power transmission at two locations. Through bevel gear we will give drive to drilling centre and grinding centre. The model facilitate us to get the operation performed at different working centre simultaneously as it is getting drive from single power source. Objective of this model are conservation of electricity (power supply), reduction in cost associated with power usage, increase in productivity, reduced floor space.
\end{abstract}

\section{Introduction}

Industries are basically meant for Production of useful goods and services at low production cost, machinery cost and low inventory cost. Today in this world every task have been made quicker and fast due to technology advancement but this advancement also demands huge investments and expenditure, every industry desires to make high productivity rate maintaining the quality and standard of the product at low average cost In an industry a considerable portion of investment is being made for machinery installation. So in this paper we have a proposed a machine which can perform operations like drilling, sawing, shaping, some lathe operations at different working centers simultaneously which implies that industrialist have not to pay for machine performing above tasks individually for operating operation simultaneously.

Economics of manufacturing: According to some economists, manufacturing is a wealth-producing sector of an economy, whereas a service sector tends to be wealth-consuming. Emerging technologies have provided some new growth in advanced manufacturing employment opportunities in the Manufacturing Belt in the United States. Manufacturing provides important material support for national infrastructure and for national defense.

\section{Literature Review}

Before starting our work we have undergone through many research papers which indicates that for a production based industries machine installation is a tricky task as many factor being associated with it such as power consumption (electricity bill per machine), maintenance cost, no of units produced per machine i.e. capacity of machine, time consumption and many more....

Some research papers which have led us to approach to the idea of a machine which may give solution to all these factors are as follows:

Heinrich Arnold1 November 2001: Rather long re-investment cycles of about 15 years have created the notion that innovation in the machine tool industry happens incrementally. But looking at its recent history, the integration of digital controls technology and computers into machine tools have hit the industry in three waves of technology shocks. Most companies underestimated the impact of this new technology. This article gives an overview of the history of the machine tool industry since numerical controls were invented and introduced and analyzes the disruptive character of this new technology on the market. About 100 interviews were conducted with decision-makers and industry experts who witnessed the development of the industry over the last forty years. The study establishes a connection between radical technological change, industry structure, and competitive environment. It reveals a number of important occurrences and interrelations that have so far gone unnoticed. 
Dr. Toshimichi Moriwaki (2006): Recent trends in the machine tool technologies are surveyed from the view points of high speed and high performance machine tools, combined multifunctional machine tools, ultra precision machine tools and advanced and intelligent control technologies.

Frankfurt-am Main, 10 January 2011. : The crisis is over, but selling machinery remains a tough business. Machine tools nowadays have to be veritable "jack of all trades", able to handle all kinds of materials, to manage without any process materials as far as possible, and be capable of adapting to new job profiles with maximized flexibility. Two highly respected experts on machining and forming from Dortmund and Chemnitz report on what's in store for machine tool manufacturers and users.

Multi-purpose machines are the declarations of independence. The trend towards the kind of multipurpose machining centers that are able to cost efficiently handle a broad portfolio of products with small batch sizes accelerated significantly during the crisis. "With a multi-purpose machine, you're less dependent on particular products and sectors", explains Biermann

\section{Proposed Methodology}

In this project we will generally give the power supply to the shaft on which a bevel gear is mounted on it, and a second bevel gear at a right angle to it has been mounted on a drill shaft to which a drill bit is being attached. At one end of the shaft is connected to power supply, other end is being joined to a circular disc ,through this circular disc scotch yoke mechanism is being performed (rotator y motion is converted to reciprocating motion). Also in between these two , a helical gear is mounted which transfer its motion to other helical gear which is mounted on a shaft consist of grinding wheel

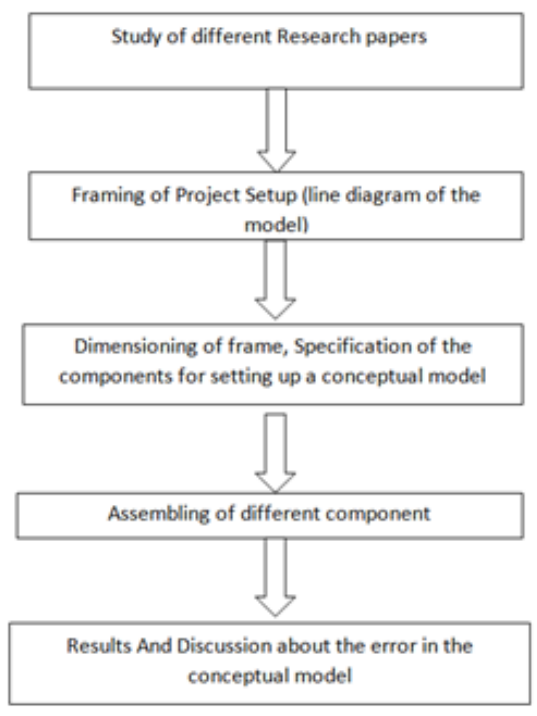

\section{Experimental Set-Up}

In this conceptual model we have involved the gear arrangement for power transmission at different working centers, basically gear or cogwheel is a rotating machine part having cut teeth, or cogs, which mesh with another toothed part in order to transmit torque, in most cases with teeth on the one gear being of identical shape, and often also with that shape on the other gear. Two or more gears working in tandem are called a transmission and can produce a mechanical advantage through a gear ratio and thus may be considered a simple machine. Geared devices can change the speed, torque, and direction of a power source. The most common situation is for a gear to mesh with another gear; however, a gear can also mesh with a non-rotating toothed part, called a rack, thereby producing translation instead of rotation.

\section{Working Principle} works:

There are only two major principle on which our proposed machine(conceptual model) generally

1. Scotch-Yoke mechanism

2. Power transmission through gears.

a. Bevel gears 


\section{Scotch Yoke Mechanism}

The Scotch yoke is a mechanism for converting the linear motion of a slider into rotational motion or vice-versa. The piston or other reciprocating part is directly coupled to a sliding yoke with a slot that engages a pin on the rotating part. The shape of the motion of the piston is a pure sine wave over time given a constant rotational speed.

\section{Power Transmission Through Gears}

Bevel gears are gears where the axes of the two shafts intersect and the tooth-bearing faces of the gears themselves are conically shaped. Bevel gears are most often mounted on shafts that are 90 degrees apart, but can be designed to work at other angles as well. The pitch surface of a gear is the imaginary toothless surface that you would have by averaging out the peaks and valleys of the individual teeth. The pitch surface of an ordinary gear is the shape of a cylinder. The pitch angle of a gear is the angle between the face of the pitch surface and the axis.

\section{Working of the Model:}

In the conceptual model of "Multi-Functional operating machine" we are giving supply to the main shaft (refer fig.13), as we move along the axis of shaft we have mounted a pair of bevel gears, through the pinion shaft we are giving drive to drill shaft through belt-pulley arrangement, we have installed the stepped pulley in the arrangement therefore we can made the speed variation. Now again as we move along the axis of main-shaft further we have again used the bevel gear arrangement to give the drive to grinding center.

As we can see that the scotch yoke mechanism is directly fabricated to the main shaft and have same angular velocity as that of main-shaft.

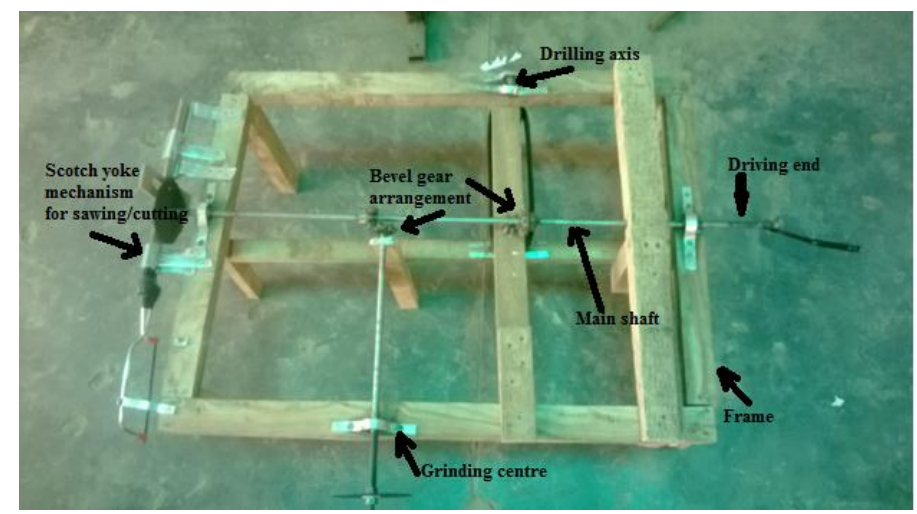

Figure1: Over View Of The Model

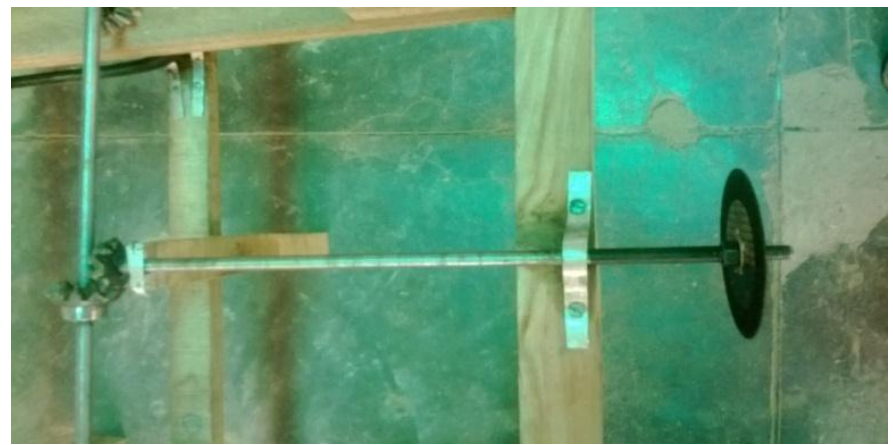

Figure 2: Grinding Centre getting power through bevel gear arrangement 


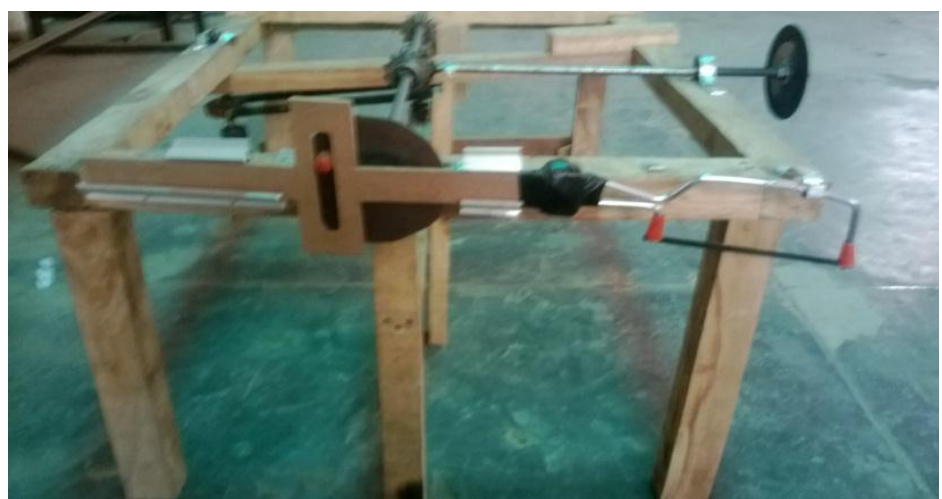

Figure 3: Sawing/ Cutting end using Scotch Yoke Mechanism

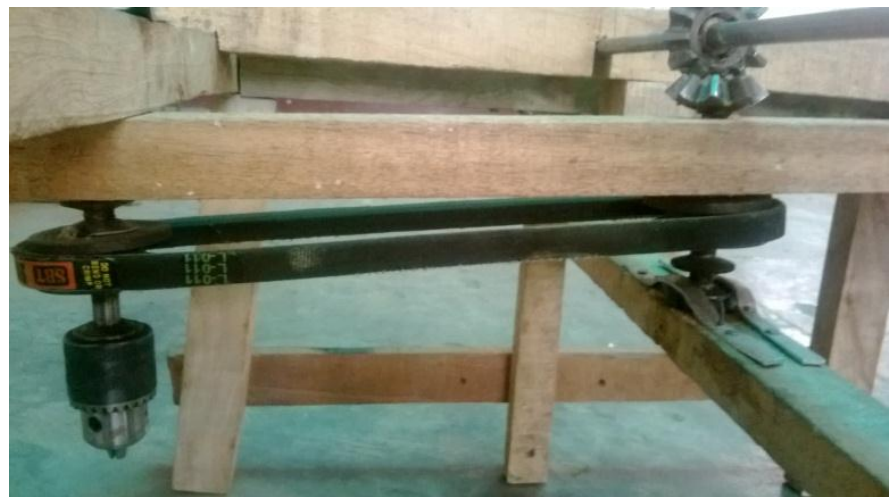

Figure 4: Drilling centre getting drive through bevel gear and belt-pulley arrangement

\section{Specification of the Components used in the conceptual model:}

i. Frame of the model: length $=2.5 \mathrm{ft}$., width $=2 \mathrm{ft}$., height $=1 \mathrm{ft}$.

ii. Bevel gears: no. of teeth $\mathrm{T} 1=12, \mathrm{~T} 2=9$.

iii. For gear: Base radius. $=2 \mathrm{~cm}$, pitch cone angle $=55 \mathrm{deg}$, pitch dia. $=4 \mathrm{~cm}$.

iv. For Pinion Base radius. $=1.4 \mathrm{~cm}$, Pitch Cone Angle $=35$ Deg, pitch dia. $=2.8 \mathrm{~cm}$.

v. Shaft dia. $=10 \mathrm{~mm}$ (approx.), shaft length $=2.5 \mathrm{ft}$.

vi. Roller bearings of inside dia. $=9.5 \mathrm{~mm}$

vii. Material of bevel gears is mild steel

viii. Shaft is also of mild steel.

ix. Length of Belt $=12$ inch.

x. Thickness of belt $=14 \mathrm{~mm}$.

xi. Diameter of pulley $=60 \mathrm{~mm}$.

xii. $\quad$ Type of belt used $=$ V-belt.

xiii. Frame is made of wood (neem).

xiv. Operation can be performed are: sawing/cutting, drilling, grinding (we have used a prototype wheel (dia. $12 \mathrm{~cm}$ ) in-place of grinding wheel).

\section{Result}

Our main aim is to represent our innovative concept, we have taken some useful data from our conceptual model and tried to evaluate the percentage deviation from the standard calculated values which is as follows:-

Since pitch radius of pinion is $r_{p}=1.4 \mathrm{~cm}$, pitch radius of gear $r_{g}=2 \mathrm{~cm}$.

By the relation between pitch cone angle and velocity ratio we can find the velocity ratio as we have pitch cone angle for both gear and pinion as $55 \mathrm{deg}$. and $35 \mathrm{deg}$.

$\tan \Upsilon_{\mathrm{p}}=\frac{\sin \theta}{\frac{\omega p}{\omega g}+\cos \theta}$ where $\theta$ is the angle between the shaft.

On putting $\theta=90^{\circ}$ and $\Upsilon_{\mathrm{p}}=35^{\circ}$ we get $\frac{\omega p}{\omega g}=1.428$ i.e. our velocity ratio is 1.428

Now for the two complete revolution of main shaft the Drilling shaft and grinding shaft should have no of revolution $=2.856$ (theoretically) 
But from our model the no of revolution measured at drilling and grinding axis $=2.67$ ( i.e. two complete revolution plus $240^{\circ}$ rotation.

Percentage Error in power transmission $=\frac{2.856-2.67}{2.856} * 100=6.51 \%$

Now diameter of circular disc of Scotch yoke mechanism $=7.9 \mathrm{~cm}$

Actual measured effective stroke length of yoke $=7.73 \mathrm{~cm}$

Percentage error in the stroke length $=\frac{7.9-7.73}{7.9} * 100=2.15 \%$

Similarly many values of rpm at drilling and grinding axis can be measured on changing the input; in this conceptual model feed to the work piece is given through the work table.

Since the model is subjected to friction therefore there is a error of $6.51 \%$ and $2.15 \%$ during power transmission and transverse motion of sawing blade respectively.

For Drilling and Grinding operation we have used the identical bevel gears therefore both operation will have same velocity ratio.

Table 1: difference in between theoretical power transmission and actual power transmission

\begin{tabular}{|l|c|c|c|}
\hline S no. & No. of revolution given to main shaft & Theoretical revolution at driven end & Actual revolution at driven end \\
\hline 1 & 1 & 1.428 & 1.335 \\
\hline 2 & 2 & 2.856 & 2.67 \\
\hline 3 & 3 & 4.284 & 4.22 \\
\hline 4 & 4 & 5.712 & 5.65 \\
\hline 5 & 5 & 7.14 & 7.075 \\
\hline 6 & 6 & 8.568 & 8.503 \\
\hline
\end{tabular}

Table 2: difference in between theoretical effective stroke length of yoke and actual effective stroke length of yoke for different no. of revolution of main shaft

\begin{tabular}{|l|c|c|c|}
\hline S no. & No. of revolution given to main shaft & $\begin{array}{c}\text { Theoretical effective stroke length at } \\
\text { driven end }\end{array}$ & $\begin{array}{c}\text { Actual effective stroke length at } \\
\text { driven end }\end{array}$ \\
\hline 1 & 1 & 7.9 & 7.73 \\
\hline 2 & 2 & 7.9 & 7.73 \\
\hline 3 & 3 & 7.9 & 7.73 \\
\hline 4 & 4 & 7.9 & 7.73 \\
\hline 5 & 5 & 7.9 & 7.73 \\
\hline 6 & 6 & 7.9 & 7.73 \\
\hline
\end{tabular}

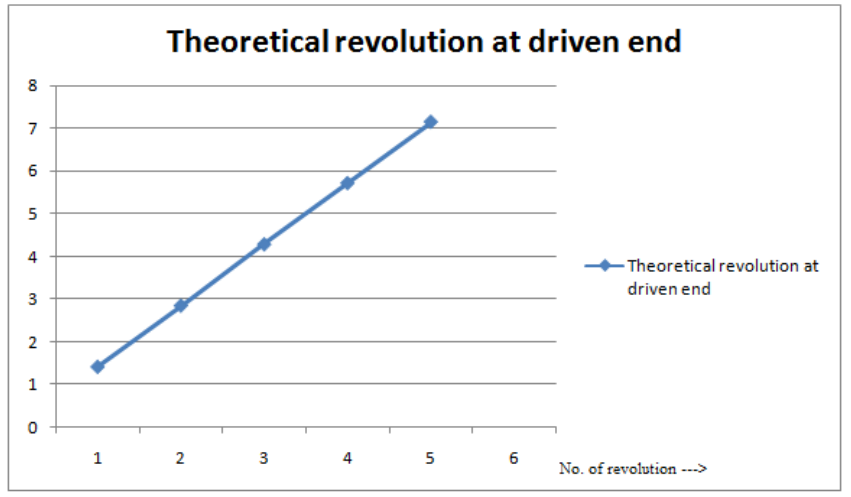

Figure 20: Plot to show theoretical revolution at driven end

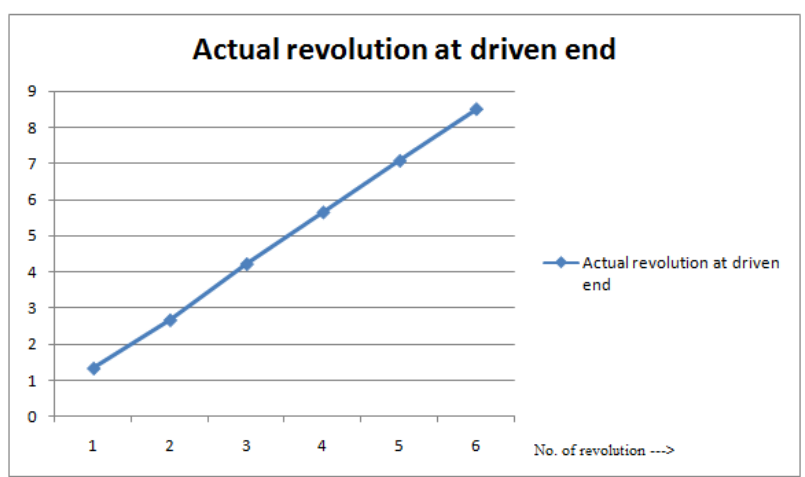

Figure 21: Plot to show actual revolution at driven end 


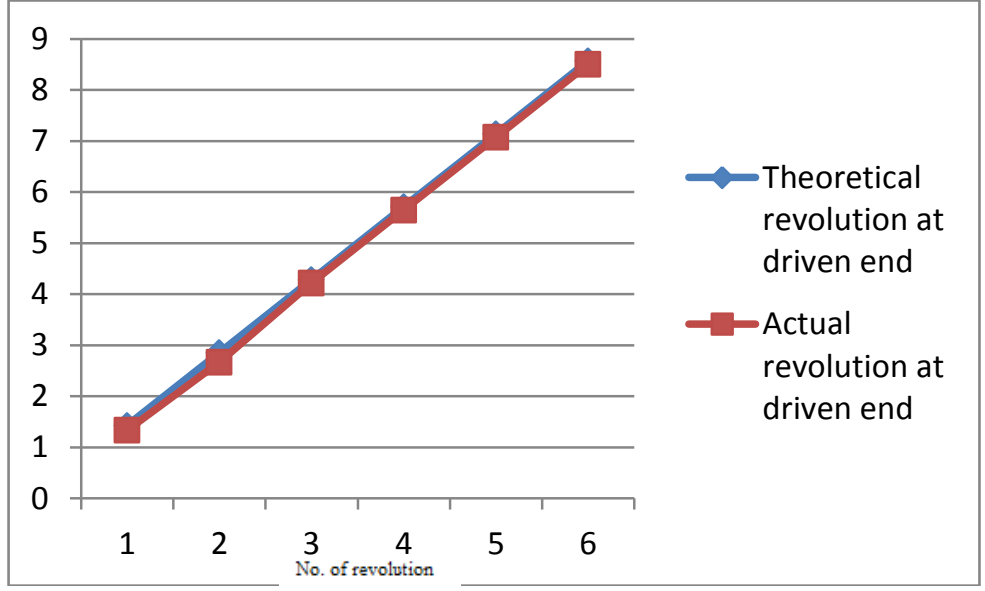

Figure 22: Plot to show error in between Actual and theoretical power transmission at driven end

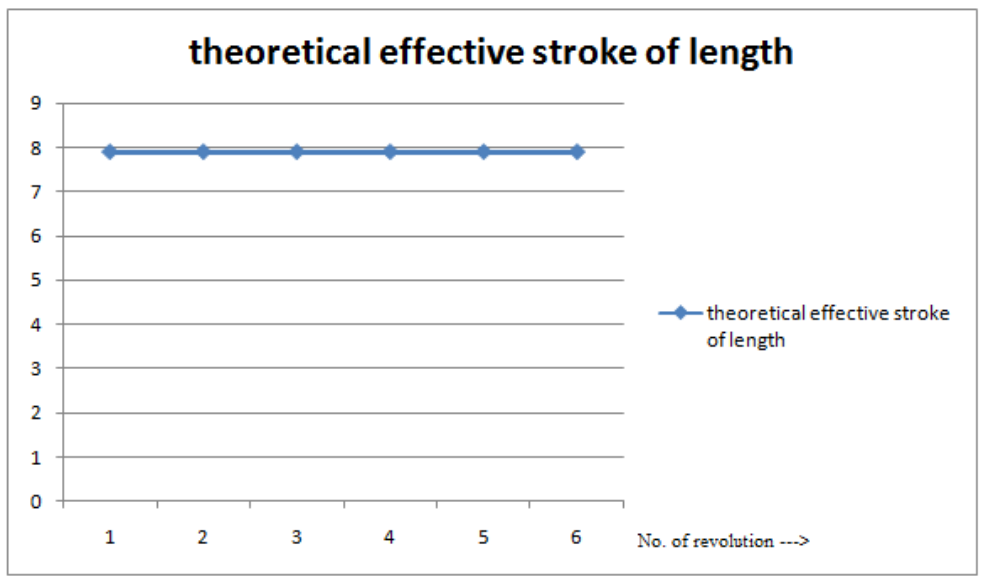

Figure 23: plot to show theoretical effective stroke of length at driven end

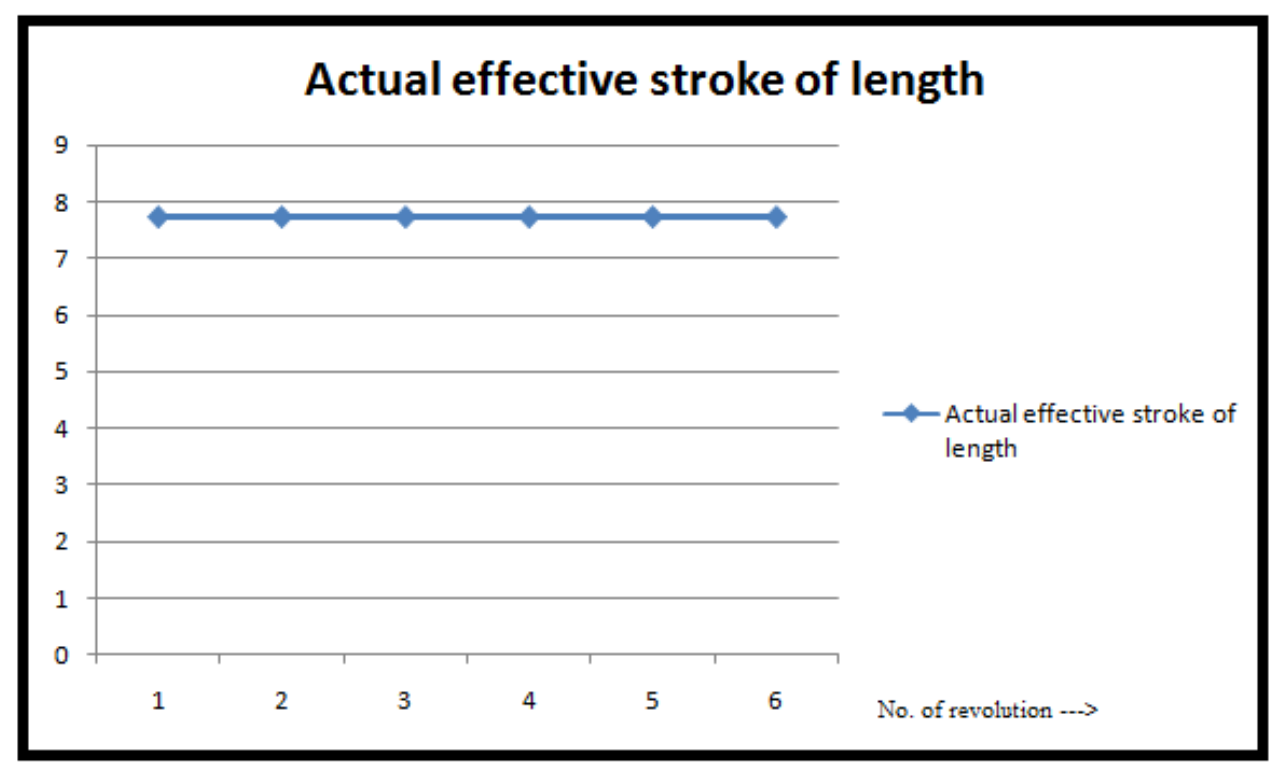

Figure 24: plot to show actual effective stroke of length at driven end 


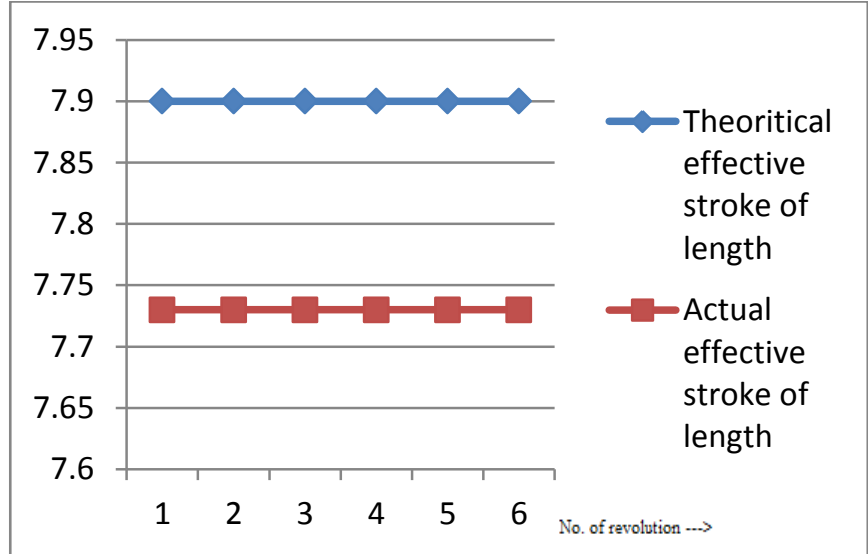

Figure 25: Plot to show error in between Actual and theoretical effective stroke of length

\section{Conclusion}

We can see that all the production based industries wanted low production cost and high work rate which is possible through the utilization of multi-function operating machine which will less power as well as less time, since this machine provides working at different center it really reduced the time consumption up to appreciable limit.

In an industry a considerable portion of investment is being made for machinery installation. So in this paper we have proposed a machine which can perform operations like drilling, sawing, grinding at different working centers simultaneously which implies that industrialist have not to pay for machine performing above tasks individually for operating operation simultaneously.

\section{References}

[1]. Heinrich Arnold1"The recent history of the machine tool industry and the effects of technological change "University of Munich, Institute for Innovation Research and Technology Management, November 2001.

[2]. Dr. Toshimichi Moriwaki "Trends in Recent Machine Tool Technologies" Professor Department Of Mechanical Engineering Kobe University ,NTN Technical Review No.74(2006).

[3]. T. Moriwaki "Multi-functional machine tool", Department of Industrial and Systems Engineering, Setsunan University, Neyagawa, Japan CIRP Annals - Manufacturing Technology DOI:10.1016/j.cirp.2008.09.004

[4]. $\quad$ Frankfurt am Main "Multi-purpose machines ensure enhanced “, 10 January 2011.

[5]. "Selecting and Planning the Process of Manufacture: Dr. Pulak M.Pandey. http://paniit.iitd.ac.in/ pmpandey

[6]. Wikipedia.

[7]. Fadooengineers.com.

[8]. www.Scribd.com. 